\title{
IMPACT OF CONSUMER PERCEPTION TOWARDS PURCHASE OF CLOTHING
}

\author{
V. PREMALATHA ${ }^{\mathbf{1}}$, R. VENKATARAVI ${ }^{2}$ \& K. SANGEETHA ${ }^{\mathbf{3}}$ \\ ${ }^{1,2}$ Gandhi Gram Rural Institute, Deemed University, Tamil Nadu, India \\ ${ }^{3}$ Bharathiyar University, Tamil Nadu, India
}

\begin{abstract}
The clothing manufacturers, designers, dealers, wholesalers and retailers in Tuticorin district produce and sell clothes at reasonable prices, utilizing recent technology, comparatively in metropolitan cites. The shopping Centers are designed and promoted to serve diverse groups of consumer with widely differing needs. The advanced technology has enhanced the beauty of dress and sense with embellishment, as each and every age group personality affords their wardrobe according to their taste and preference. Clothing acts as a symbol of belonging or alternation for every consumer. Consumer satisfaction arise when the clothing manufacturers provides them with benefits that satisfy their needs and wants. The study focus on consumer's perception about purchasing behavior, clothing element and fabric composition, promotional strategy and factors influencing clothing behavior.

KEYWORDS: Clothing, Value Addition, Design Pattern, Consumer Literacy, Place of Purchase \& Advertising
\end{abstract}

Received: Nov 02, 2017; Accepted: Nov 22, 2017; Published: Jan 12, 2018; Paper Id.: IJTFTFEB20182

\section{INTRODUCTION}

Tuticorin district, a port and Pearl City obtain economic prosperity through shipping, fishing, salting, baking, and agriculture and clothing production. The towns such as Kovilpatti, Ettayapuram, Eyral and headquarters of Tuticorin district, Tuticorin city earn the wealth through spinning, weaving, apparel production and retailing. Kovilpatti, a match town has many spinning industries, textiles and apparel industries which act as factory outlet and retail showrooms for branded and unbranded clothing. People at Ettayapuram, a home of Tamil poetry Bharathiyar earn their lives through handloom and power sectors. They are practicing with traditional looms such as pit looms, representing the culture. Eyral earned the name in retail shopping of clothes at cheaper price. The success of textiles and apparel industries and retail forms depend on two elements that is tradition and innovation. Consumer requires product worth of money they use for purchase. Consumer approach on clothing purchase based on AIO (activities interest and opinion) is to buy as their needs. Consumers buy clothes based on age, gender, income, occupation and location. Economic situation of consumer decides the clothing allowance of the family. Clothing preferred by man for the whole family depends on the clothing budget. Decision making of consumer in purchase of clothes differs on the value of clothing, selling points used by sales people and mode of payment. Whether the effectiveness of clothing purchasing decision of consumer has been achieved is a big question, and so far little efforts have been undertaken to study the consumer's preference in clothing selection. The present study would throw light on the present scenario in perception of purchasing behavior of clothing among consumer in Tuticorin district. 


\section{OBJECTIVES OF THE STUDY}

The textile manufacturer's weavers, designers, wholesalers and retailers create and expose the custom apparels to the consumers based on the person's preference. The online retailers recommend clothing designers to potential buyers through computers which produce custom clothing reported by Aqua king (2018). The sellers and buyers are closely related with each other. The study has been undertaken about the sellers' opinion about the consumer preference of clothing and the consumer perception about purchase of clothing.

Consumer literacy is an essential for consumers trying to navigate world today. Consumers require literacy to make decision related to safety, choice, managing financial transactions and resources. Consumer literacy is an ingredient for economics success and consumer with enough knowledge and skills to make them capable of effective consumer decision making. The consumer purchasing decision on clothes is based on the knowledge of the consumers. The researcher concentrates on the consumer's perception in purchasing behavior of clothes.

- To know about the seller's opinion about the clothing shoppers perception.

- To study the consumer preference for clothing in terms of clothing design and fabric composition.

- To study about the consumer opinion about promotional activities in clothing purchase.

- To study about the factors influencing clothing behavior.

- To analyze the consumer's preference in context of socio-economic profile.

\section{RESEARCH DESIGN}

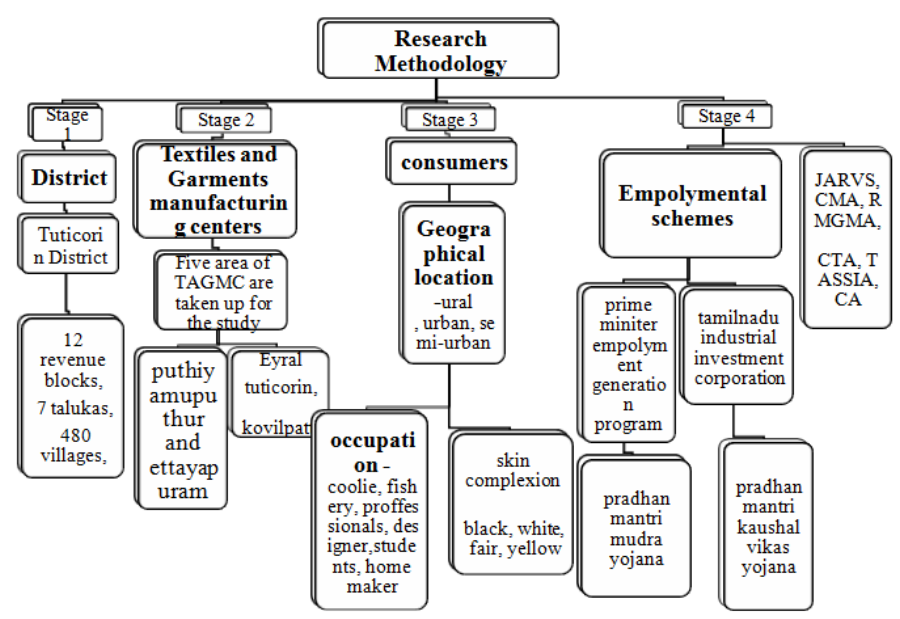

Tuticorin district is situated in the southeastern corner of Tamil Nadu state, which is known for pearl cultivation. Pudhiyamputhur is a small town located at Ottapidaram taluk in Tuticorin district. It is $17 \mathrm{~km}$ from Tuticorin towards west, $5 \mathrm{~km}$ from Ottapidaram towards south and $15 \mathrm{~km}$ from Puthukkottai towards north. The Pudhiyamputhur is called as Kutty Japan, Thennagathin Tirupur and Readymade City. Around 5000 families are living in this area. Ettayapuram earned their wealth through small scale weaving sectors. Tuticorin also comprises of spinning mills, garment manufacturing units and clothing retail shops. Next to match industries, Kovilpatti is also earning a precise name in apparel production through factory outlets. Eyral earned the name in retail shopping of clothes at cheaper price.

Associations such as javuli and readymade viyaparikal sangam (JARVS), clothing manufacturers association 
(CMA), readymade garment manufacturers association (RMGMA), clothing traders association (CTA), tiny and smallscale industries association (TSSIA), consumer rights protection council (CRPC) are leading the manufacturers and retailers for promotion and rectification of defaults. The governmental schemes such asTCIDS - Textile Center Infrastructure Development Scheme, APES - Apparel Park for Exports Schemes, Scheme for Integrated Textiles Parks (SITP) TUFS - Technology Up gradation Fund Scheme, ATUF - Amended Technology Up gradation Funds Scheme, and Prime minister Employment generation program-PMGP and Tamil Nadu industrial investment corporation-TIIC, Mahalir Thittam by the Tamil Nadu Corporation for development of women Ltd (TNCDW) are imparting a main role for proper functioning of industries and generating employment opportunities.

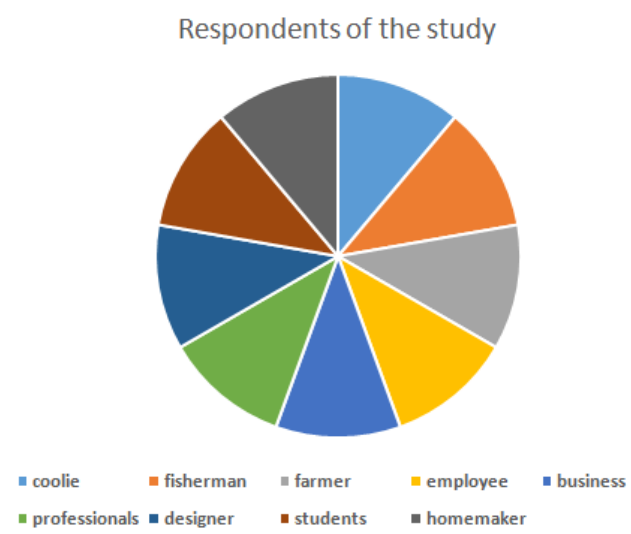

Data was collected using interview schedule from 900 respondents. The data has been analysed by using the Statistics Package for Social Science [SPSS] with the following research tools; Chi-Square Tests, percentage analysis, descriptive analysis, factor analysis.

\section{ANALYSIS AND INTERPRETATION}

\section{Seller's Opinion about Clothing Shopper's Perception}

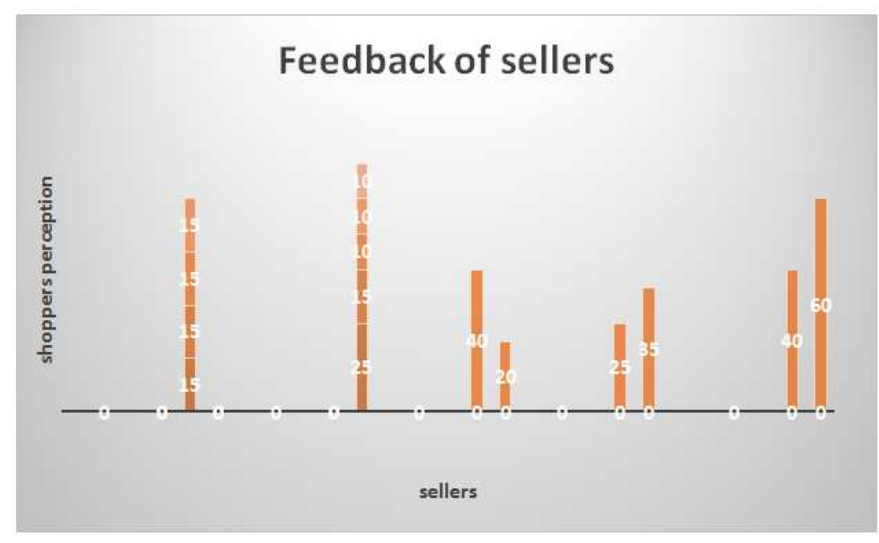

Figure 1 


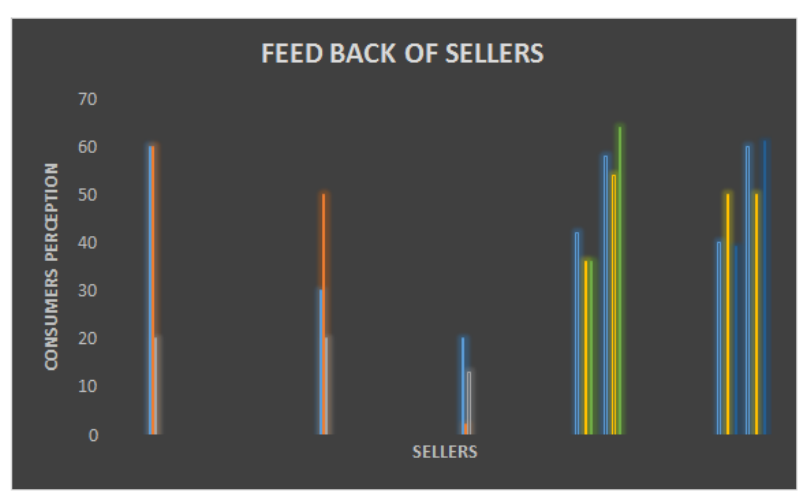

Figure 2

Figure 1, 2 showed the feedback collected from the manufacturer, wholesaler, designer, retailer and salesperson recruited in industry, boutique, wholesale shop, retail, showroom and factory outlet. Retail store variety included catalogue showroom, Fashion Avenue, specialty showroom, hypermarket and discount store. The shopper's perception about the place of purchase and clothing elements, properties, brand and labels were collected from the personnel's related with clothing sales.

\section{Consumer Perception about Clothing}

The consumer perception about clothing elements, design pattern, texture selection, color selection, comfort characters of fabric, place of purchase and promotional strategy was analyzed through collecting data from consumers.

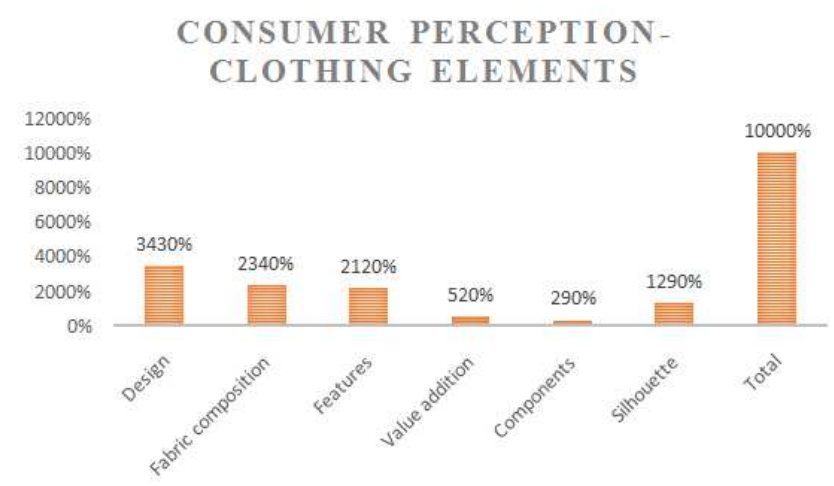

Figure 3

One third of the consumers preferred design in clothing selection, nearly one half of the consumers preferred fabric composition, one fifth of the consumers preferred features, more than one tenth of the consumers preferred silhouette, Minimum amount of consumers preferred value addition and components. 


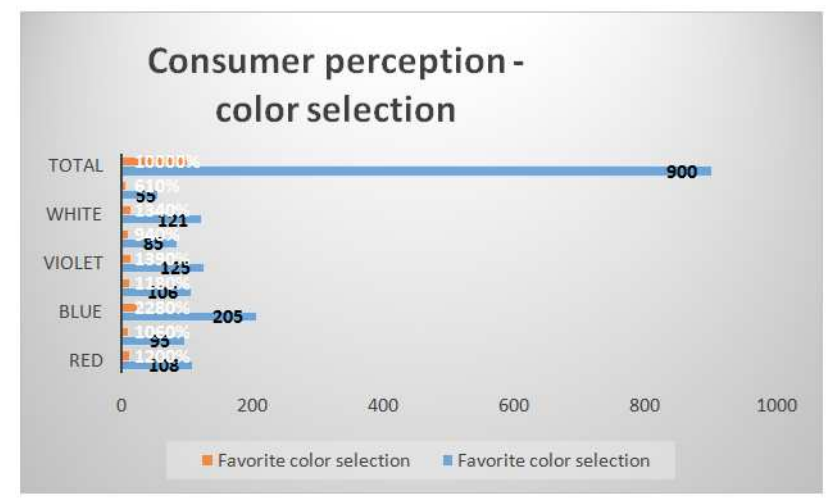

Figure 4

$6.1 \%$ consumers preferred black, 9.4\% consumers preferred green, $10.6 \%$ consumers prefer yellow, $11.8 \%$ consumer preferred orange, $12.0 \%$ consumers preferred red, $13.4 \%$ consumers preferred white, and $13.9 \%$ consumers preferred violet and $22.8 \%$ consumers preferred blue in clothing selection.

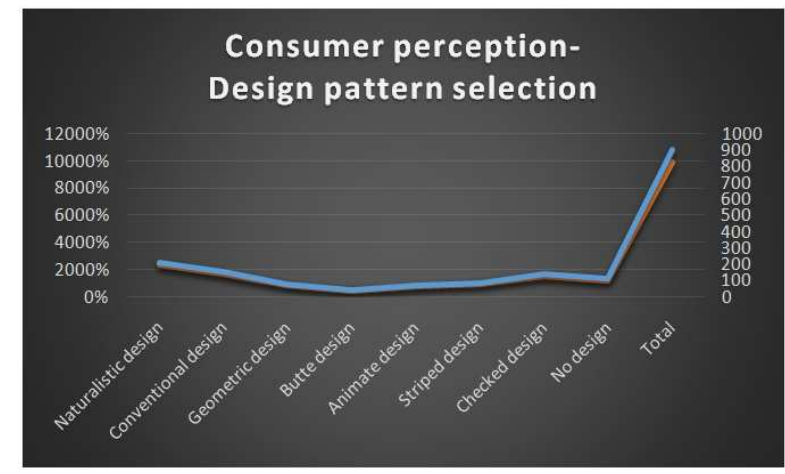

Figure 5

$23.8 \%$ consumers preferred naturalistic design, $17.0 \%$ consumers preferred conventional design, $15.3 \%$ consumers preferred checked design, $12.6 \%$ consumers preferred no design, $9.7 \%$ consumers preferred striped design, $8.8 \%$ consumers preferred geometric design, $7.8 \%$ consumers preferred animate design and $5.1 \%$ consumers preferred butter design.

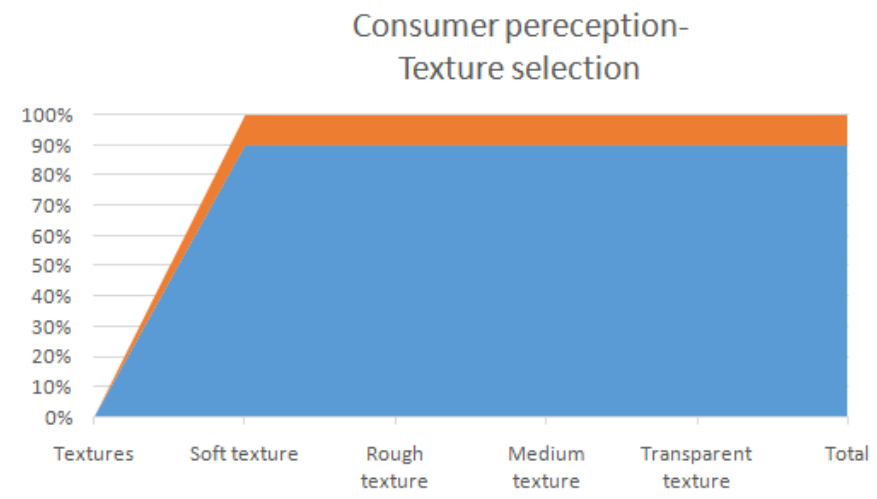

Figure 6

The majority of the consumers preferred soft texture material followed by medium texture material, rough texture material is accepted by one fourth of consumers and transparent texture material is accepted by the least consumers. 


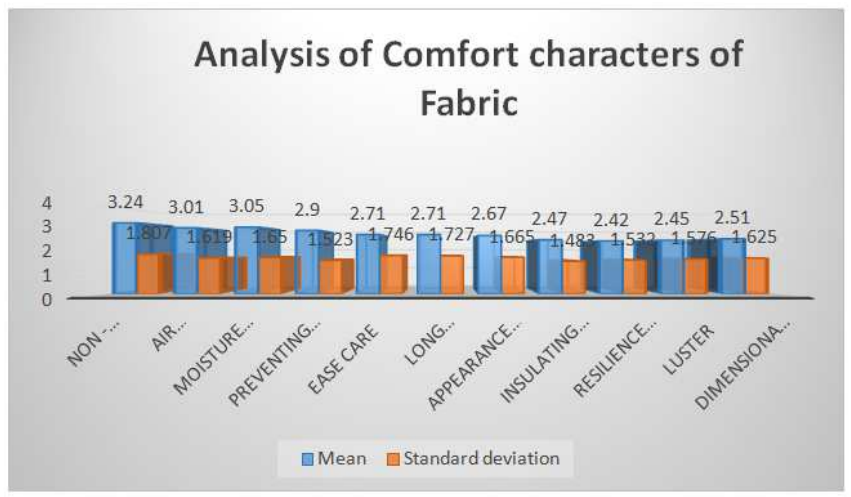

Figure 7

The figure showed that apprehension of comfort characters of fabric which was analyzed from the consumers. The consumers mostly prefer the fabric with non-irritant character, air permeability and moisture absorbency. The consumers prefer ease care and long standing life in equal importance. The consumers are having awareness about appearance retention, insulating power, dimensional stability, luster, static build up and resilience in fabric structure to some extent.

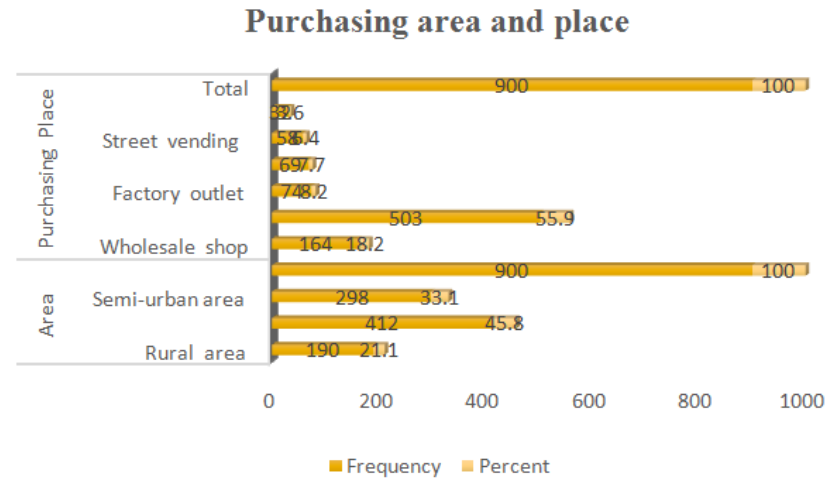

Figure 8

$18.2 \%$ of consumers selected wholesale shop for their clothing purchase, $55.9 \%$ preferred retail shop, $8.2 \%$ preferred Factory outlet, 7.7\% preferred online shopping, 6.4\% preferred street vending, and 3.6\% preferred selling at home. The figure also showed the purchasing area of consumers. The purchasing area of most of the consumers was urban and one third of consumers were semi-urban and nearly one half of consumer was rural place.

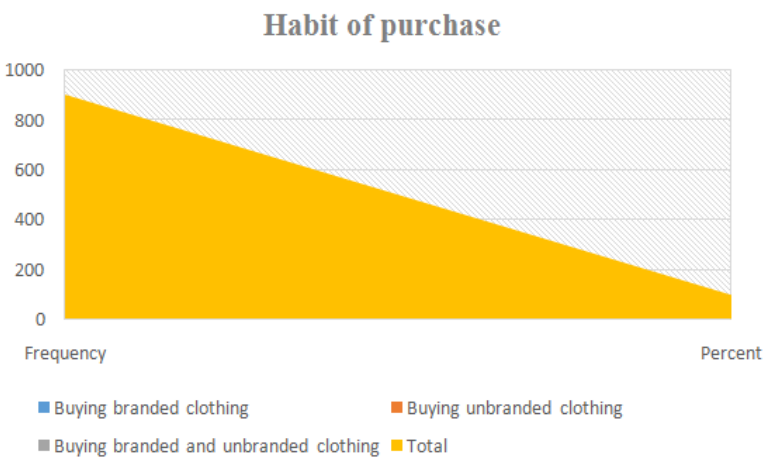

Figure 9 
Nearly one third of the consumers bought branded clothing, nearly two fifth of consumers bought both branded and unbranded clothing, more than one third of consumers buy unbranded clothing.

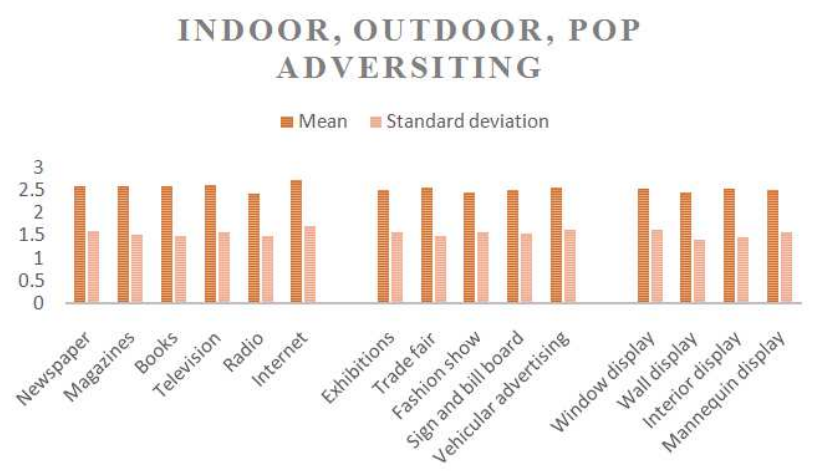

Figure 10

The consumers gave more concentration to internet, rather than newspaper and magazines. The shoppers were attracted by vehicular advertising rather than fashion show interior display, which got the highest score than wall display.

\section{Factors Influencing Clothing Behaviour}

Factor Analysis

\begin{tabular}{|l|l|c|}
\hline \multicolumn{3}{|c|}{ KMO and Bartlett's Test } \\
\hline Kaiser-Meyer-Olkin Measure of Sampling Adequacy. & .902 \\
\hline \multirow{3}{*}{ Bartlett's Test of Sphericity } & Approx. Chi-Square & $6.608 \mathrm{E} 3$ \\
\cline { 2 - 3 } & Df & 78 \\
\cline { 2 - 3 } & Sig. & .000 \\
\hline
\end{tabular}

This table shows the factor analysis of various factors influenced by consumers at the time of purchasing clothes. The KMO measures the sampling adequacy (which determines, if the responses given with the sample are adequate or not), which should be closed than 0.5 for a satisfactory factor analysis to proceed. Kaiser recommends 0.5 (value for KMO as minimum (barely accepted). The KMO measure was 902, which was greater than of 0.5, and therefore can be barely accepted. Durability factor (.806) was highly loaded on first factor, Fabric and Construction factor (.853) were highly loaded on the second factor, and Price factor (.779) was highly loaded on third factor.

\section{SUMMARY OF FINDINGS}

- One third of the consumer's preferred design in clothing selection.

- Majority of the Consumers preferred blue in clothing selection (22.8\%).

- Maximum Consumers preferred naturalistic design (23.8\%).

- Mainstream of the consumers preferred soft texture material $(37 \%)$.

- $\quad$ One half of the consumer's selected woven fabric.

- Majority of the consumers preferred cotton (50.4\%).

- $\quad$ Maximum of the consumers preferred saree and blouse $(25.4 \%)$.

- Majority of the consumers preferred pant and shirt (29.6\%). 
- The large numbers of respondents bought the branded and unbranded products $(37.3 \%)$

- $\quad$ Majority of the respondents purchased clothes for clothing need (34.2\%).

- $\quad$ One third of consumers selected dress based on purpose.

- Maximum consumers selected the brand depending on the proper stitching construction (26.7\%).

- One third of consumers considered the financial status and social influence while selecting occasional dress.

\section{SUGGESTION}

- Clothing reflects human history, showing progress in materials availability, mastering of newer technology, culture and society. It is suggested to motivate the consumer for choosing the style that suits than instead of blindly following fashion. It is also suggested to select clothes that didn't represent people and objects in a realistic way, but expressed the artistic ideas and feelings.

- It is suggested for the consumers to identify the suitable creative clothing.

- Today's consumer demand more values for money through different levels of comfort, desirability, and functionality. It is suggested to dictate the life style of the consumer through wardrobe expansion and changes in the basic plan.

- It is suggested to insist the consumer, to dress at home as in public rather than using more casual wears and to select more clothes with new styles

- "To cooperate with consumers is the first task". India is witnessing change on life style of large section of population it is the need of the consumer to understand the emerging markets and consumers has become a challenge for the corporate world, especially in creating and managing a brand and number of people visits the show room with the thought of purchasing the comfort and quality clothing.

- It is suggested by the members of RMGMA and CTA to implement ready-made clothing market in pudhiyamputhur for once in a week, for facilitating the retailers of Tamil Nadu regarding their purchase.

- Thus, the suggestions to overcome the problems to improve the efficiency of consumers are presented in the report. Individuals can become the best consumers of clothes, by following the suggestions that provide selfsatisfaction.

\section{CONCLUSIONS}

The study revealed the levels of understanding and knowledge on clothing among the consumers in Tuticorin district. It is found from the study that, socio-economic aspects influence the effectiveness of consumer in purchasing decision. The study also brought to light the problems of consumers. The following are the problems reported by the study,

- Untrained consumers

- Lack of consumer perception in purchasing decision on the concept of clothing

- Impromptus color selection in accordance with their personality 
- Un interesting fact about clothing life cycle

- Nil grasp of consumers about clothing elements and fabric composition

- Less importance of comfort characters of fabrics by consumers

- Not giving importance to special clothing due to economic condition.

- Less attraction towards the promotional activities.

- Less awareness about brands, lack of anticipation about labels and packaging.

- Less concentration on impact of factors influencing clothing behavior.

\section{REFERENCES}

1. Prakashvasudevan, technical, textiles: the sun rise industry yojena, vol.60, October 2016, pg.25.

2. Kadolph. J. quality asswence for textiles and apparels, Fairchild production, New Delhi, 1998.pg.202.

3. Jonathan o" Brien, category management in purchasing, first south Asian kogan page ltd London. 2010, pg.124, $125,127$.

4. Kamal khurana, draping and patterns making for fashion design, sonali publication, New Delhi, 2012.

5. Jordijuani, jeano logia, Indian textiles journal, July 2016, pg. 66.

6. Uma sekaran and roger bougie, John Wiley and sons, research methods for business, ltd. Delhi, 2010, pg.285.

7. M. Chandrakumar et al., Consumer Perception Analysis using Perceptual Mapping of Popular Tea Advertisements in Coimbatore District, Tamil Nadu, International Journal of Agricultural Science and Research (IJASR), Volume 6, Issue 4, July - August 2016, pp. 81-88

8. Gordanacolovic, management of technology system in apparel industry, wood head publishers India pvt, ltd, New Delhi, 2011.

9. Suresh miera, sapna Gandhi, mamta pathania, consumer protection in India, concept publishing, new Delhi, 2012.

10. T.ramasamy, principles of management, Himalaya publishing house Mumbai, 2014, pg.103, 102.

11. Dr.shefali Massey; dr.shahnazjahan. Infant's clothing selection practices followed by mothers, textiles trends, 2011, (43).

12. Aqua king, all fresher's designers to make outfits based on your choice, the new Indian express, Tirunelveli, Thursday, November 30, 2017. 
